\title{
Uso do seriado Black Mirror no ambiente acadêmico
}

\author{
Use of Black Mirror series at academic environment
}

\section{Uso de la serie Black Mirror en el ambiente académico}

PATRICIA LUPION TORRES

LEONARDO SILVA

DANIELLE CRISTINE BOARON GRUNEWALDER

\section{Resumo}

O presente artigo tem como objetivo apresentar o resultado de uma pesquisa, desenvolvida por pesquisadores do Programa de Pós-Graduação Stricto Sensu em Educação de uma universidade privada do Estado do Paraná. Considerando a crescente busca por inovações no ambiente educacional, foi realizado em sala de aula uma atividade utilizando uma série televisiva que provoca uma reflexão crítica sobre uso da tecnologia e comportamento da sociedade. Foi realizada uma discussão reflexiva em relação ao episódio Queda Livre, do seriado Black Mirror e posteriormente um roteiro de análise fílmico com perguntas sobre os aspectos técnicos, impacto na formação e contribuição para a disciplina. Os resultados obtidos demonstram o interesse na dinâmica e que a inserção desse tipo de mídia em sala de aula permitiu, além da absorção do conteúdo, o envolvimento do estudante como sujeito crítico, capaz de compreender e refletir sobre as informações e mensagens contidas nos conteúdos midiáticos disponíveis.

Palavras-chave: Tecnologias Educacionais. Educação. Prática Docente. Black Mirror.

\section{Abstract}

This present study aims to present the result of a study, developed within the research of Stricto Sensu postgrad in Education at a large private university of Paraná State.

\footnotetext{
a Pontifícia Universidade Católica do Paraná (PUCPR), Curitiba, PR, Brasil. Doutora em Engenharia de Produção - Mídia e Conhecimento, e-mail: patricia.lupion@pucpr.br

b Pontifícia Universidade Católica do Paraná (PUCPR), Curitiba, PR, Brasil. Mestre em Educação, email: leonardo.goncalves@pucpr.br

c Pontifícia Universidade Católica do Paraná (PUCPR), Curitiba, PR, Brasil. Mestre em Educação, email: danielle.cristine@pucpr.br
} 
Considering the growing seek for innovations in the educational environment, an activity was carried out in the classroom using a television series that provokes a critical reflection on the use of technology and society's behavior. A reflective discussion was about to the episode Nose Dive, from the series Black Mirror and later a script of film analysis with questions about the technical aspects, impact on formation and contribution to the discipline. The results obtained demonstrate the interest in the dynamics and that the inclusion of this type of media in the classroom allowed, besides the content absorption, the student's involvement as a critical subject, able to understand and reflect on the information and messages contained in the available media contents.

Keywords: Educational Technologies. Education. Teaching Practice. Black Mirror.

\section{Resumen}

El presente estudio para presentar el resultado de un estudio de casos, desarrollado dentro de la investigación de la stricto sensu postgradación en educación en una universidad privada del Estado de Paraná. Con la creciente demanda por innovaciones en el ambiente educativo, se realizó en el aula una actividad utilizando una serie televisiva que provoca una reflexión crítica sobre el uso de la tecnología y el comportamiento de la sociedad. Se realizó una discusión reflexiva sobre el episodio "Queda Livre", de la serie Black Mirror y posteriormente un guión de análisis fílmico con preguntas sobre los aspectos técnicos, impacto en la formación y contribución a la disciplina. Los resultados demuestran el interés en la dinámica y que la inserción de ese tipo de medios en el aula permitió, además de la absorción del contenido, la implicación del estudiante como sujeto crítico, capaz de comprender y reflexionar las informaciones y mensajes contenidos en los contenidos mediáticos disponible.

Palabras clave: Tecnologia Educativas. Educación. Práctica Docente. Black Mirror.

\section{Introdução'}

Cada vez mais presentes na vida das pessoas, os dispositivos tecnológicos facilitam o acesso à informação e estão modificando a forma como nos comunicamos e vivemos em sociedade. Devido ao barateamento dos custos e a massificação do acesso à internet banda larga, os jovens estão mais conectados e envolvidos ativamente nesse mundo digital. Esse contato precoce, por outro lado, deve ser

\footnotetext{
1 Procedimentos éticos: todos os participantes envolvidos nesta pesquisa tiveram suas identidades preservadas.
} 
acompanhado e mediado, de modo que sejam capazes de fazer uma leitura crítica das mensagens recebidas das mais distintas mídias.

Uma das grandes mudanças observadas neste século é a transposição da comunicação de massa para a comunicação interativa. Antes, o indivíduo era apenas um espectador passivo sentado em frente da televisão, e hoje com a internet, atua como produtor de mensagens que comunica sua opinião e compartilha informações nos diversos canais sociais (SILVA, 2001).

Nesse sentido, “[...] estamos nos deslocando de um mundo de consumidores para um mundo de criadores de informação" (PALFREY; GASSER, 2011, p. 138). Atualmente não existe uma distinção clara entre as programações voltadas para a internet e para a televisão, com essa multiplicação e integração das mídias, qualquer usuário com acesso à rede pode expressar-se, emitir opinião, criar conteúdos e destacar-se. A imensidão de vídeos criados e o aumento de pessoas que se tornaram produtores de conteúdo nos últimos anos, representa a presença e a importância desse movimento.

Outra característica dessa nova geração, é a autodidaxia, isto é, por meio do contato com as tecnologias de informação e comunicação (TIC) e movidos pelo interesse em conhecer e utilizar novos recursos e softwares, aqueles que nasceram e cresceram em meio a esse cenário digital, desenvolvem sozinhos ou colaborativamente na relação entre pares, o conhecimento necessário, bem como, novas habilidades cognitivas de forma espontânea (BELLONI, 2012).

Por outro lado, observa-se que as novas mídias e formas de absorção dos conteúdos, quando aplicadas individualmente, não são capazes de gerar reflexão nos estudantes. Na prática relatada posteriormente foi possível observar na fala dos estudantes que a utilização das novas mídias e as novas formas de absorção dos conteúdos ainda são dependentes de intervenção de professores que facilitam a percepção das teorias que estão sendo usadas na nova mídia. Essa intervenção do professor e também o apoio de materiais didáticos são de extrema relevância para a criação de uma reflexão crítica, propositiva e criativa.

Considerando que "os meios de comunicação de massa se converteram no ambiente onde crescem as novas gerações" (FERRÉS, 1996, p. 9), muitas vezes, por várias horas frente à televisão ou computador, os jovens adquirem valores, habilidades 
e conhecimentos inconscientemente ao assistir desenhos, filmes, propagandas e novelas. E, em meio a "esse turbilhão de imagens formam [...] sua personalidade ao mesmo tempo (mas provavelmente não da mesma forma) que suas vivências e suas percepções do mundo exterior, real, concreto" (BELLONI, 2005, p. 65). Cabe alertar que muitas universidades não se atentam a essa questão, o que resulta em estudantes "[...] sem o mínimo preparo para um uso racional desses meios" (FERRÉS, 1996, p. 9). Considerando essa nova realidade posta, as instituições de ensino deverão formar os estudantes de forma que possam sintetizar e analisar um volume enorme de informações que mudam cada vez mais rápido, permitindo assim um controle mais efetivo das inovações.

Ao aproximar o ensino à realidade vivida fora dos muros da instituição, além de aproveitar as aptidões e habilidades naturais com as tecnologias para a inserção de práticas mais envolventes e significativas, forma-se cidadãos mais críticos em todas as esferas da vida, pois o uso de recursos audiovisuais para análise e reflexão em sala desenvolve, de forma espontânea, a competência crítica necessária para o consumo de imagens provenientes das mais distintas mídias (FERRÉS, 1998).

Ademais, é preciso considerar a experiência dos alunos, para partir de onde eles estão, "do que eles preferem, da relação que estabelecem com as mídias, para ajudá-los a ampliar sua visão de mundo, sua visão crítica e seu senso estético" (MORAN, 2007, p. 56).

É nesse contexto que surge um novo campo do saber traduzido no conceito de mídia-educação que

[...] trata de uma dupla dimensão: como meios da pedagogia e como uma educação para os meios. Isto é, uma educação para as mídias, tomando as TIC como objeto de estudo; e uma educação pelas mídias, tomando as TIC como ferramenta pedagógica. Uma educação com e através das mídias que não apenas prepare os indivíduos para o uso de novos recursos tecnológicos, mas que os forme para uma apropriação crítica e consciente de seus conteúdos éticos e estéticos (LAPA; BELLONI, 2012, p. 182).

O bombardeamento de imagens e mensagens recebidas diariamente, vindas das mais diversas mídias, desafia instituições de ensino a formar sujeitos com senso crítico, capazes de compreender e refletir a respeito dos conteúdos midiáticos disponíveis. Educar para a compreensão e interação com a mídia implica em formar para 
a análise do papel político, econômico e social dos grandes conglomerados de comunicação do formato, estrutura e linguagem de produtos audiovisuais e materiais impressos, interpretação e crítica dos conteúdos midiáticos e reflexão sobre o impacto da mídia nas sociedades contemporâneas (ELEÁ; DUARTE, 2016, p. 13).

Educar para a mídia significa preparar o aluno para uma análise crítica e analítica de seu conteúdo. Têm-se como exemplos de meios de educar para as mídias, ou formas de integração das tecnologias nos processos educacionais o uso de filmes de ficção e documentários, de materiais sonoros, de audiovisuais ou digitais (programas de rádio e TV, jogos e softwares educacionais), bem como a utilização de recursos digitais para o desenvolvimento de atividades colaborativas (ELEÁ; DUARTE, 2016).

O uso das mídias pode proporcionar ao estudante a abertura para se tornar um ator ativo no processo de ensino e aprendizagem, mas pode também o colocar na posição de mero receptor passivo, ou seja, o uso da tecnologia na sala de aula depende de um planejamento prévio e de uma mediação pedagógica adequada.

Considerando que mídias por si só não garantem mudanças significativas no processo ensino aprendizagem e que os integrantes dessa geração são essencialmente colaboradores em todas as esferas da vida (COUTO, 2014), é basilar a investigação de práticas educacionais focadas na educação para as mídias, que promovam a aprendizagem colaborativa, a reflexão, o pensamento crítico, a autonomia e a produção do conhecimento mais profundo e significativo.

\section{O uso pedagógico dos filmes}

Muito utilizadas nos momentos de lazer e entretenimento, as obras cinematográficas ainda são pouco valorizadas como fonte de conhecimento no ambiente educacional. Ultrapassando o conceito simplista da utilização apenas de vídeos produzidos com fins educativos, inúmeros filmes dos mais distintos gêneros podem ser incluídos nos processos de ensino e aprendizagem, desde que os objetivos estejam bem delineados para que não se percam a proposta e o teor pedagógico.

Segundo Moreira e Nejmeddine (2015) existem dois tipos de vídeos que podem ser usados em sala: os vídeos didáticos-pedagógicos e os vídeos educativos. A 
primeira categoria refere-se aos materiais primordialmente elaborados para fins educacionais e que possuem a intenção de instruir. Trata-se de vídeos científicos, técnicos e documentários, os quais não são narrativos. Já o segundo tipo, são vídeos que não foram produzidos com uma intenção educativa, mas que possuem potencial pedagógico, tais como os filmes ficcionais, próprios da linguagem cinematográfica. Dessa forma, observa-se que, com base em um projeto pedagógico estruturado, inúmeros vídeos podem ser utilizados em sala, mesmo aqueles que não são inicialmente didáticos.

$\mathrm{Na}$ experiência vivenciada, por se tratar de um curso de Design, o uso de vídeos em sala de aula permite aos estudantes um exercício prático de leitura crítica de imagens, reforçando os conteúdos com o apoio do professor para enfatizar a atenção em determinados momentos.

Observa-se também, segundo Moreira e Monteiro (2012, p. 5, grifo dos autores), que em algumas práticas “[...] muitas vezes, cai-se em situações de facilitismo didático, quer delegando nos documentos fílmicos toda a capacidade de transmissão de informação numa aula, quer reduzindo o seu papel a questões meramente motivacionais". Além disso, esses autores ainda destacam que "com frequência a incorporação destes objetos de aprendizagem audiovisuais faz-se improvisando, sem estabelecer um plano e uma estratégia pré-definida o que, necessariamente, acaba por lhes retirar eficácia pedagógica” (MOREIRA; MONTEIRO, 2012, p. 5).

Fatores culturais, podem determinar que os recursos audiovisuais sejam vistos apenas como diversão e entretenimento pelos meios educacionais, que delimitam o uso "[...] como mero complemento de atividades verdadeiramente educativas, como a leitura de textos, por exemplo, ou seja, como um recurso adicional e secundário em relação ao processo educacional propriamente dito" (DUARTE, 2009, p. 18). Além disso, "enquanto os livros são assumidos por autoridades e educadores como bens fundamentais para a educação das pessoas, os filmes ainda aparecem como coadjuvantes na maioria das propostas de política educacional" (DUARTE, 2009, p. 19).

Os filmes estão muito presentes na cultura e no dia a dia dos estudantes, assim, utilizar esse recurso em classe é auxiliar a instituição "a reencontrar a cultura ao mesmo tempo cotidiana e elevada, pois o cinema é o campo no qual a estética, o lazer, 
a ideologia e os valores sociais mais amplos são sintetizados numa mesma obra de arte" (NAPOLITANO, 2009, p. 11).

Devido à popularização dos serviços de vídeo, a qualquer hora e lugar é possível ter acesso a milhares de filmes, séries e programas de TV. No entanto, "um filme apresentado em um canal de televisão, por mais didático que seja, não está inserido numa proposta formal de ensino” (KENSKI, 2011, p. 86). Por outro lado, segundo a autora, isso não significa que o mesmo filme não possa ser utilizado em uma situação educativa em sala de aula, desde que haja um planejamento pedagógico para tal. Nesse sentido,

sua apresentação deve ser condicionada ao tipo de aluno, ao conteúdo que se quer trabalhar e aos objetos de aprendizagem que se pretende alcançar. É preciso uma preparação prévia dos alunos para "olharem" o filme, colocarem-se em atenção e predisposição para a observação e análise crítica do que vai ser visto. É preciso, depois, canalizar, todo o envolvimento dos estudantes com as cenas vistas para a formulação de debates, conversas e atividades comunicativas entre eles, de forma que orientem a reflexão sobre o conteúdo que deve assimilado e trabalhado criticamente (KENSKI, 2011, p. 86).

O planejamento prévio do docente e sua mediação pedagógica são fundamentais para a construção coletiva de conhecimento pelos discentes. A mera “apresentação de um filme ou programa de televisão — sem nenhum tipo de trabalho pedagógico anterior ou posterior à ação — desloca professores e alunos para uma forma receptiva e pouco ativa de ensino" (KENSKI, 2011, p. 87).

Assim, como forma de sistematizar algumas das possibilidades de utilização didática dos vídeos, Ferrés (1996) propõe seis modalidades de uso: a vídeo-lição, o vídeo-apoio, o vídeo processo, o programa motivador, o programa monoconceitual e, por fim, o vídeo interativo.

$\mathrm{Na}$ vídeo-lição alguns conteúdos sistematizados são transmitidos aos estudantes, assemelhando-se a uma aula tradicional expositiva, porém a figura do professor é substituída pelo vídeo. O vídeo-apoio, por sua vez, estabelece uma interação entre as imagens e a fala do professor, que pode adequar a exposição de acordo com o ritmo de aprendizagem dos estudantes. Já o vídeo processo é considerado uma das possibilidades mais criativas no uso didático do vídeo, pois os estudantes se tornam protagonistas no processo, participando com criatividade, compromisso e dinamismo na criação das imagens. No programa motivador, parte- 
se de um programa audiovisual em formato de vídeo utilizado para fomentar um trabalho posterior à exibição, isto é, baseia-se na pedagogia do depois. Já o programa monoconceitual está entre o vídeo-apoio e o programa motivador, pois por se tratar de vídeos curtos, geralmente mudos, que abordam um conceito, um fenômeno ou um fato, o professor pode utilizá-los para transmitir a informação, bem como, facilitar a explanação, congelando a imagem, repetindo, entre outros. Por fim, com o vídeo interativo o receptor é tão ativo quanto o emissor, pois a sequência e a manipulação de imagens podem ser definidas pelo estudante ou professor de acordo com nível e ritmo de aprendizagem. É a interação entre o vídeo e o computador.

Alguns autores sugerem maneiras de incluir propostas pedagógicas voltadas para a utilização de filmes no planejamento pedagógico de uma disciplina. Napolitano (2009) propõe duas fases para práticas presenciais: planejamento das atividades e análise do filme, cada qual subdividindo-se em vários momentos.

$\mathrm{Na}$ fase inicial, primeiramente sugere que o filme seja inserido no planejamento geral, articulando-o com os conteúdos e conceitos que serão estudados e focando nas competências e habilidades que se pretende atingir. Em seguida, deve-se selecionar uma sequência de filmes a serem trabalhados ao longo do ano, de modo que sejam articulados entre si. O próximo passo é buscar algumas informações básicas sobre o meio cinematográfico (história do cinema, principais estilos, etc.) antes de utilizar o filme em sala. Por fim, o professor deve conhecer a preferência dos estudantes, isso significa que não deve impor seus gostos a eles.

Na segunda fase, o primeiro passo é solicitar que os estudantes assistam o filme na integra, de preferência fora do horário de aula, exceto em casos em que esses, em sua maioria, não tenham como assistir em outro local. Um fator essencial nesse processo é o fornecimento de um roteiro de análise do filme, devidamente elaborado com base nos objetivos da atividade. O autor propõe também, se o professor julgar necessário, a disponibilização de alguns textos de apoio relacionados ao filme, como críticas, entrevistas com o diretor, atores, entre outros. Na sequência, os estudantes devem ser organizados em grupos, estimulando-os para uma análise aprofundada, problematizando o filme. É importante formalizar por escrito ou em painéis ilustrados o que foi analisado nessa etapa. Por fim, pode ser interessante organizar uma síntese da discussão grupal, relacionando com o conteúdo da disciplina, de modo que as 
diferentes opiniões e as várias formas de assimilação sobre o que foi visto e os conceitos e habilidades envolvidos sejam valorizadas.

Por sua vez, Moreira e Nejmeddine (2015) apresentam uma proposta metodológica para ambientes on-line com quatro fases principais para uma adequada utilização pedagógica do filme nesse contexto virtual de aprendizagem.

Primeiramente, na fase denominada Preparação ou Planificação, o professor deve selecionar e assistir o vídeo, verificando se está de acordo com o currículo, os objetivos e o perfil dos estudantes. Deve elaborar um guião de leitura global e funcional do vídeo e uma grelha de observação (aspectos positivos e negativos, descrição do contexto, temática, entre outros) que serão disponibilizados aos discentes. É importante que o docente identifique como o vídeo será acessado (pela web, na plataforma ou se será preciso adquiri-lo).

$\mathrm{Na}$ sequência, na fase Visualização, Leitura e Análise, o professor deve fornecer aos estudantes o guião e a grelha, incentivando a visualização ativa e a avaliação dos conceitos abordados. Por se tratar de uma tarefa realizada individualmente, os discentes podem pausar, rever e analisar detalhadamente todos os aspectos sobre a narrativa relacionados com os conteúdos da disciplina.

$\mathrm{Na}$ terceira fase, intitulada Desconstrução do Recurso, Debate e Reflexão, o professor disponibiliza no ambiente virtual de aprendizagem referenciais teóricos pertinentes à temática, que, somados às informações contidas nas grelhas de observação, são utilizados no debate e reflexão acerca do filme assistido, de modo que os estudantes tenham espaço para expressarem o que gostaram ou não, sentiram ou perceberam, construindo, então, a essência da aprendizagem.

Por fim, na etapa Conclusão e Verificação, é feita uma síntese final da atividade, na qual o professor pode sugerir novos recursos, leituras, sites ou atividades complementares relacionadas com a temática de estudo.

As duas propostas apresentadas ilustram que independente do ambiente educacional, seja presencial ou on-line, é possível propor práticas pedagógicas utilizando os mais distintos filmes, de modo que o estudante se torne ativo e envolvido no processo de ensino e aprendizagem. Nessa perspectiva,

[...] o filme educativo torna-se algo mais do que um momento de emoção e diversão podendo converter-se numa experiência viva e interessante, que ajuda os estudantes a alargarem conceitos, a pensarem e a confrontarem-se criticamente com outras realidades, 
a interiorizarem valores que se dispersariam numa incerta pesquisa, a agarrar ideias que não cabem dentro de definições, nem se compreendem totalmente através da leitura de um texto (MOREIRA; MONTEIRO, 2012, p. 5).

Não há dúvidas de que incluir obras fílmicas no ambiente educacional representa uma possibilidade de transformar uma experiência rotineira do cotidiano em uma experiência de aprendizagem significativa, ancorada em aspectos relevantes da estrutura cognitiva e emocional do aluno (TORRES; KUCHARSKI; MARRIOT'T, 2014). Isso ocorre quando motivamos os alunos intimamente, quando eles acham sentido nas atividades que propomos, quando consultamos suas motivações profundas, quando se engajam em projetos para os quais trazem contribuições, quando há diálogo sobre as atividades e a forma de realizá-las" (MORAN, 2018, p. 6). Esse autor ainda destaca que é necessário conhecer o perfil do estudante, bem como "acolhê-los afetivamente, estabelecer pontes, aproximar-se do universo deles, de como eles enxergam o mundo, do que eles valorizam, partindo de onde eles estão para ajudá-los a ampliar sua percepção, a enxergar outros pontos de vista, a aceitar desafios criativos e empreendedores" (MORAN, 2018, p. 6).

Ademais, evidencia-se que “[...] a transmissão/produção de saberes e conhecimentos não é prerrogativa exclusiva da escola (embora ela tenha um importante papel a desempenhar nesse processo), mas que acontece também em outras instâncias de socialização” (DUARTE, 2009, p. 67, grifo do autor). Dessa forma, entender o papel dos meios audiovisuais na vida dos estudantes, torna-se fundamental para compreensão desse novo perfil de jovens que chegam às universidades.

Tomando como base as metodologias citadas e considerando o perfil dos estudantes de Design, que foram objeto de pesquisa, optou-se por criar uma metodologia adaptada, ilustrada na Figura 1. 
Figura 1 - Metodologia Usada

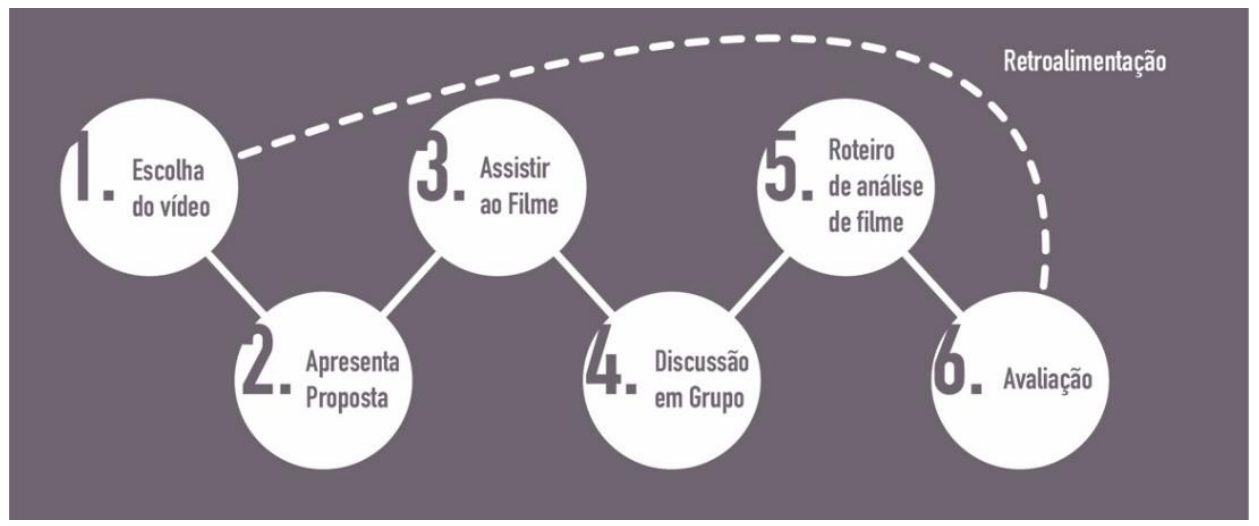

Fonte: Autores (2018).

Na metodologia utilizada, a fase 1 também consiste na escolha do vídeo que será exibido aos estudantes, ressaltando que para essa escolha deve ser levado em consideração o perfil da turma, o conteúdo que pretende ser trabalhado e objetivo da utilização da mídia. Na fase 2 é apresentada a proposta aos estudantes, explicando como será desenvolvida a atividade, alinhando assim as expectativas deles diante ao resultado esperado. Nessa fase, também o professor pode solicitar aos estudantes que realizem a fase 3, que consiste em assistir ao filme, como atividade fora da sala de aula. Para o desenvolvimento desse artigo, foi optado pela exibição do filme em sala, considerando o perfil da turma e também por se tratar de uma disciplina de Vídeo Digital Aplicada, na qual o objeto de estudo é a produção de materiais audiovisuais. Sendo assim, o professor fez a escolha pois poderia ao longo da exibição do episódio realizar comentários que fossem pertinentes aos estudantes. Após a exibição do filme, inicia-se a fase 4, na qual é realizada uma discussão em grupo para captar as percepções do grupo e trocar as experiências de cada um ao assistir ao filme. O professor nesse momento pode gerar provocações com intuito de enriquecer o debate na turma. Por fim, os estudantes realizam um roteiro de análise de filme, que tem como principal objetivo captar a impressão individual de cada estudante perante o material e a experiência vivenciada, essa é a quinta fase do processo. A fase 6 consiste na avaliação do docente em relação ao processo, e as considerações deverão ser utilizadas no momento de elaboração de uma nova atividade que utilize do mesmo método, gerando assim uma retroalimentação. 


\section{Caminhos da pesquisa: procedimento metodológico e experiência vivenciada}

Esse artigo descreve o resultado de uma pesquisa-formação, orientada por uma abordagem qualiquantitativa realizada em uma universidade particular de grande porte do Estado do Paraná. Para o entendimento a respeito do problema investigado, os dados foram obtidos por meio de um questionário semiestruturado.

Segundo Santos, Carvalho e Pimentel (2016, p. 24) “a pesquisa-formação é uma metodologia de pesquisa em que o docente-pesquisador pesquisa a sua prática como docente, não separando o ato educativo do ato de pesquisar". Nesse tipo de pesquisa, “[...] o pesquisador não é apenas quem constata o que ocorre, mas também intervém como sujeito de ocorrências (SANTOS, 2005, p. 162). Ademais, “[...] não se limita a aplicar saberes existentes, as estratégias de aprendizagem e os saberes emergem da troca e da partilha de sentidos de todos os envolvidos" (SANTOS, 2005, p. 163). A autora ainda discorre que se concebe, então, esse tipo de pesquisa “[...] como processo de produção de conhecimentos sobre problemas vividos pelo sujeito em sua ação docente" (SANTOS, 2005, p. 163).

Ao utilizar uma abordagem qualiquantitativa, “[...] o pesquisador converge ou mistura dados quantitativos e qualitativos para realizar uma análise abrangente do problema de pesquisa" (CRESWELL, 2010, p. 39). Nesse sentido, os dados coletados são integrados na interpretação dos resultados gerais (CRESWELL, 2010).

Para a obtenção dos dados, optou-se pelo roteiro de análise fílmica, que se assemelha a um questionário, que é um instrumento de pesquisa composto "por um número $\mathrm{x}$ de questões apresentadas por escrito às pessoas, tendo por objetivo o conhecimento de opiniões, crenças, sentimentos, interesses, expectativas, situações vivenciadas etc." (GIL, 1999, p. 128). Esse tipo de instrumento pode ser considerado fechado, aberto ou misto, ou seja, possuir apenas questões objetivas com alternativas definidas; perguntas com espaço para respostas abertas; e por fim, uma mescla dos anteriores (questões alternativas e livres) (TACHIZAWA; MENDES, 1999). Para essa investigação, optou-se pelo questionário misto por possibilitar a coleta de dados quantitativos bem como qualitativos. 
O universo da pesquisa compreende uma mostra de estudantes universitários, diretamente ligados com as tecnologias e mídias digitais.

\section{A série Black Mirror e o episódio Queda Livre}

Criada por Charlie Brooker em 2011, a série Black Mirror foi transmitida pela primeira vez na Grã-Bretanha, mas ganhou notoriedade quando foi comprada e exibida pela Netflix, a qual produziu mais episódios para compor o seu catálogo online (WORTHAM, 2015).

Os episódios do seriado não são sequenciais, tendo diferente elencos, cenários e até mesmo realidades. Em cada um deles, a trama gira em torno de cenários de um futuro próximo que coloca novas tecnologias em um perigoso conflito com a natureza humana (NETFLIX, 2018). O nome do seriado, Black Mirror (espelho negro), faz uma alusão às telas dos dispositivos (smartphones, tablets, notebooks, entre outros) quando estão desligados, fazendo um paralelo com uma realidade sombria dos efeitos colaterais do uso das tecnologias.

O episódio escolhido para ser trabalhado com os estudantes foi o episódio Queda Livre, primeiro episódio da terceira temporada, que apresenta um universo em que todas as ações do dia a dia estão diretamente relacionadas com as redes sociais. Vivendo um uma realidade um tanto superficial, com tons pastéis e visual plástico, que simula a perfeição, os habitantes são separados por meio de uma avaliação recebida dos outros (zero a cinco estrelas), com base nas atitudes e popularidade demonstradas perante os demais. Cada habitante possui uma lente de contato fixa nos olhos que permite verificar a nota dos outros. Por meio de um dispositivo que se assemelha a um smartphone, as pessoas avaliam umas às outras simultaneamente. Nesse universo, reações como raiva, tristeza e revolta não podem ser esboçadas, pois penalizam com menos estrelas ou até mesmo o exílio da sociedade. Esse ranking da vida real é utilizado para todas as situações do dia a dia, como comprar uma casa, obter taxa diferenciada de empréstimo bancário ou manter amizades. 


\section{A experiência vivenciada}

A experiência do desenvolvimento de uma prática educacional utilizando como suporte um filme ficcional, ocorreu no ano de 2018 no curso de Design Digital de uma universidade particular de grande porte do estado do Paraná e envolveu 43 estudantes do sexto período, matriculados na disciplina Vídeo Digital Aplicado.

Com base na classificação de Moreira e Nejmeddine (2015) apresentada previamente, optou-se para essa experiência pela utilização de um vídeo que não foi produzido com uma intenção educativa, mas que possui potencial pedagógico. Assim, o objeto de estudo, conforme já comentado, foi o primeiro episódio Queda Livre, do seriado Black Mirror. Devido à característica ficcional que explora a realidade sombria dos efeitos colaterais do uso das tecnologias, essa série é de grande sucesso entre os jovens, o que tende em aumentar o interesse e o engajamento dos mesmos com as atividades propostas.

A prática ocorreu em um encontro, no qual, incialmente, o professor expôs a proposta explicitando aos estudantes o objetivo, a dinâmica da aula e os conceitos que seriam estudados. Por se tratar de uma disciplina especificamente sobre vídeo, optou-se por colocar os estudantes em contato com o episódio na íntegra durante o período da aula. Assim, com o objetivo de proporcionar uma leitura crítica das imagens, o professor fez um paralelo da visualização das cenas com a sua fala, de acordo com o ritmo e envolvimento da turma, o que gerou discussões e reflexões sobre os tópicos estudados na disciplina.

Após a conclusão do filme e debate com o grande grupo, o professor forneceu aos estudantes um roteiro de análise, para que cada qual, individualmente, fizesse uma avaliação crítica aprofundada sobre o que foi visto, bem como a contribuição dessa prática na compreensão do conteúdo da disciplina. Esse instrumento foi composto por 13 questões, sendo seis de múltipla escolha — três delas possibilitavam a escolha da opção "outros", com espaço para que o estudante pudesse apresentar um novo tópico - e sete abertas. As seis primeiras questões tinham como objetivo estimular a análise dos aspectos técnicos, tais como gênero, linguagem e valores cinematográficos. O segundo grupo de questões, composta pelas perguntas sete a nove, instigavam o estudante a refletir sobre a ideia ou mensagem principal do filme, 
além de descreverem qual a cena de maior influência ou impacto. Por fim, as questões dez a treze incentivavam o estudante a avaliar as contribuições dessa experiência para a disciplina e para sua formação, além de trazer um espaço para comentários e sugestões gerais.

\section{Análise dos dados}

Todos os estudantes que participaram dessa investigação apresentam um perfil semelhante, possuem uma faixa etária predominantemente entre os 20 e 21 anos, conforme pode ser observado no Gráfico 1.

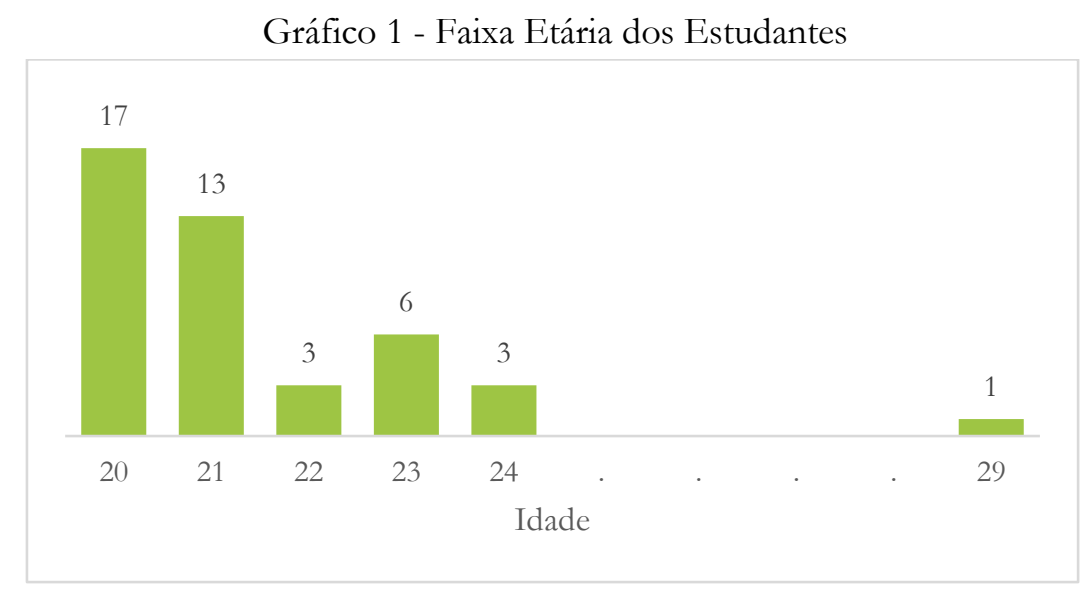

Fonte: Autores (2018).

A obra audiovisual foi classificada como sendo de ficção por 41 participantes. A penas 2 estudantes citaram a obra como sendo uma adaptação. Essa predominância no apontamento do tipo de filme demonstra que os estudantes identificaram de forma correta o que estava sendo abordado no episódio. Já no quesito de tipo de linguagem - vocabulário, um número maior de estudantes, 27, apontou a linguagem do episódio como sendo "rica". Esse apontamento pode estar relacionado ao fato que a grande maioria dos estudantes declararam que leem pouco. $\mathrm{O}$ baixo índice de leitura é também indicado pelos dados de pesquisa do Ibope - Retratos da Leitura no Brasil (2016). Segundo esse instituto de pesquisa, os brasileiros apresentam baixo índice de leitura, sendo que 44\% da população não tem o hábito de ler.

Os estudantes $(60 \%)$ classificaram o episódio como sendo de fácil entendimento e o restante deles $(40 \%)$ classificou como razoável, não tendo nenhum estudante apontado a opção de difícil entendimento. 
A disciplina na qual foi realizada a atividade trata sobre técnicas de realização de captação de imagem, sendo assim, os estudantes focaram bastante as análises nos valores cinematográficos, tendo uma avaliação positiva (ótimo e bom) do episódio, conforme Gráfico 2.

Gráfico 2 - Valores Cinematográficos

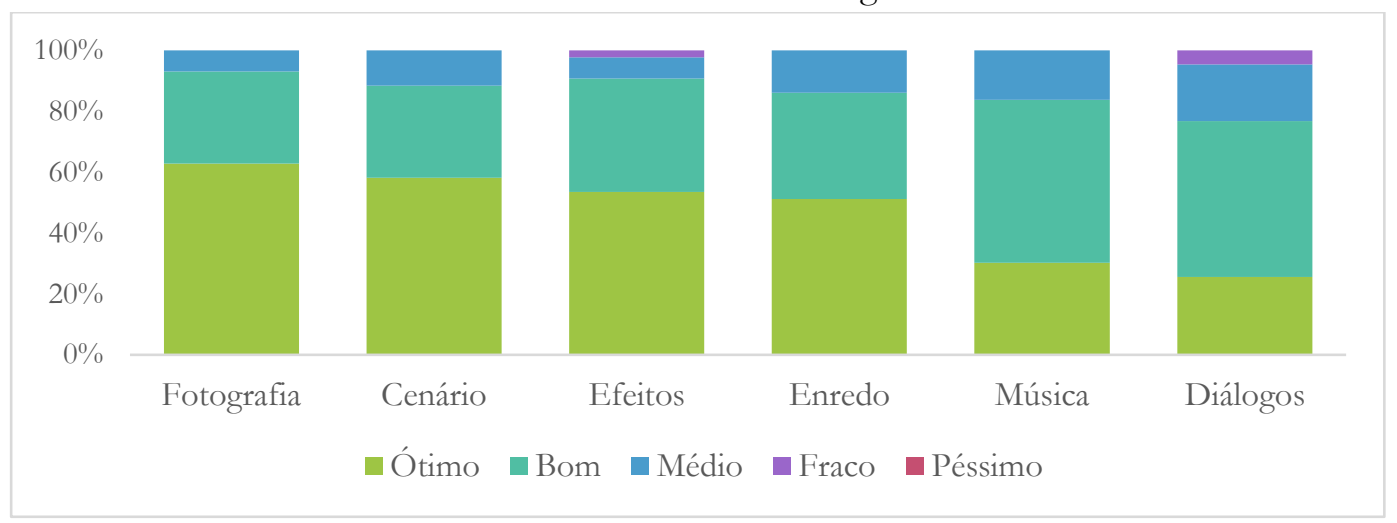

Fonte: Autores (2018).

As temáticas abordadas no seriado foram também consideradas no questionário apresentado aos estudantes. Nesta questão os estudantes podiam marcar todas as temáticas que eles identificaram no episódio, e apesar do seriado e do episódio enfatizarem a temática da tecnologia, o tema que ficou mais forte para os estudantes foram relacionados aos aspectos psicológicos, sendo marcado por $93 \%$ dos estudantes. A tecnologia aparece com 88,4\% de marcações, juntamente com os aspectos culturais. O Gráfico 3 traz todas as temáticas citadas pelos estudantes em percentual de citação. Na questão apresentada, havia a opção de citação de outras temáticas e também a temática religião, mas nenhuma das duas marcações foi realizada, por isso não constam do gráfico.

\section{Gráfico 3 - Temas Citados}

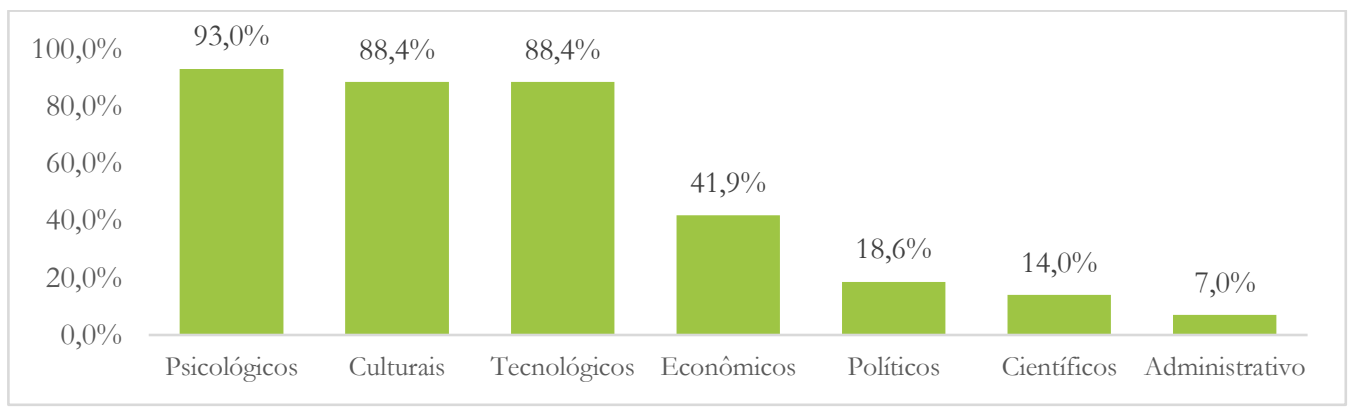

Fonte: Autores (2018). 
As cenas que geraram o maior impacto nos estudantes foram as cenas na qual a protagonista do episódio invade o casamento da "amiga" e a cena que mostra a protagonista presa em uma cela realizando uma série de xingamentos ao outro preso. O que demonstra um impacto maior nos estudantes nas cenas de confronto e sofrimento. Os estudantes relatam as cenas como segue:

- “[...] cena do casamento. O filme faz uma crítica à sociedade que se preocupa demais com a quantidade de likes. Nesta cena a personagem se liberta de todas as mentiras que vivia e fala o que se sente.” (E34)

- “[...] quando a protagonista entra na cela da prisão, e sem as lentes ela acorda para a realidade" (E22).

- "Cena na qual a personagem principal desiste de fingir em suas relações sociais e luta para chegar ao casamento que acaba fazendo a situação ficar pior ao tentar dar seu discurso" (E01).

- "A cena de maior impacto é a cena de discussão no casamento, onde a protagonista da história acaba perdendo o controle e deixa fluir seus pensamentos mais instintivos, fugindo do padrão da sociedade vigente, assim, levando-a a perceber, mais tarde, o erro que estava cometendo ao tentar ser o que não é” (E24).

- "Acredito que seja a cena final na prisão, quando se tem o processo de remoção do dispositivo ocular e a personagem se permite a liberdade de viver normalmente outra vez" (E43).

Alguns estudantes relataram cenas que não foram consenso entre os demais, porém são de extrema relevância para o entendimento do enredo. Observa-se aqui estudantes com uma sensibilidade maior para captar mesmo em cenas de menos confronto, a essência do que o episódio quer passar em relação a uma sociedade que vive de estereótipos, o que pode ser observados pelos seus comentários:

- "Quando a personagem principal fica em frente ao espelho treinando risadas dela mostra a ideia principal e quão fundo o personagem se encontra dentro do padrão social imposto" (E31).

- "A cena do aeroporto, pois vemos que pessoas com notas maiores têm acesso a melhores oportunidades e até mesmo pessoas aleatórias podem diminuir ou aumentar sua nota. Ainda há o guarda, que tem autoridade para interferir em sua nota" (E10). 
- "A cena em que o colega de trabalho aparece com uma nota baixa tentando agradar aos outros. Ela mostra pela primeira vez alguém que possui uma nota muito baixa, as atitudes que ela passa a tomar para tentar recuperá-la e a importância que as outras pessoas realmente dão a essa nota..." (E30).

Questionamos sobre a contribuição que a atividade e a discussão do audiovisual tem para o desenvolvimento da disciplina, nesse caso de Vídeo Digital Aplicado, e foi percebido que os estudantes no geral perceberam os elementos audiovisuais e a importância deles para o desenvolvimento do enredo e também colocaram alguns pontos mais amplos relacionados à atuação deles enquanto designers, demonstrando aqui que um material didático mais adequado ao perfil da disciplina e também alinhado ao público alvo permite aos estudantes uma melhor fixação do conteúdo e reflexões profundas, podendo ser comprovado pelas escritas dos estudantes:

- "Podemos observar a mudança de sentimento que as cenas querem passar por meio da edição, é possível observar os enquadramentos utilizados e analisar o motivo do uso" (E43).

- "[...] estrutura para um filme que aborda visões críticas da sociedade, levando em conta o roteiro, uso de linguagem, cenário e fotografia" (E3).

- "o episódio contribuí no conhecimento de planos e de uma direção de arte que ajuda a linha do roteiro. A música guia o sentimento do espectador, e isso ajuda na disciplina, para conhecer outros caminhos além de roteiro para guiar a finalidade do vídeo" (E7).

- "mostra uma visão diferente do impacto tecnológico em nossas vidas" (E35).

- "o episódio contribui na mostra de um possível futuro para a tecnologia, tendo nosso papel como designer" (E1).

Com relação à formação profissional e pessoal, os estudantes trouxeram inúmeras referências ao uso da tecnologia pela sociedade atual e inclusive fizeram questionamentos sobre a importância do uso deste tipo de mídia para o público universitário, fizeram ainda considerações de caráter mais existenciais, o que demonstra que fizeram uma leitura crítica do material apresentado: 
- "contribui para uma visão mais ampla com relação à tecnologia e seus consumidores" (E01).

- "ser uma pessoa melhor" (E13).

- "ao compreender os riscos que o uso da tecnologia de forma desenfreada causa, um designer consegue ter mais consciência na hora de projetar um produto, analisando os riscos e as implicações que aquilo pode trazer caso não tratemos a tecnologia de forma ética" (E26).

O grupo foi questionado também qual era a avaliação final deles em relação à atividade proposta em de uma escala que tinha como opções: Ótimo, Muito Bom, Bom, Regular e Fraco. Os dados nos mostram que 72\% dos estudantes avaliaram a atividade entre ótimo e muito bom, conforme observa-se no gráfico IV. Tal resultado permite refletir que os estudantes ficaram mais engajados na atividade e aferir o interesse por materiais mais dinâmicos e próximo a realidade deles.

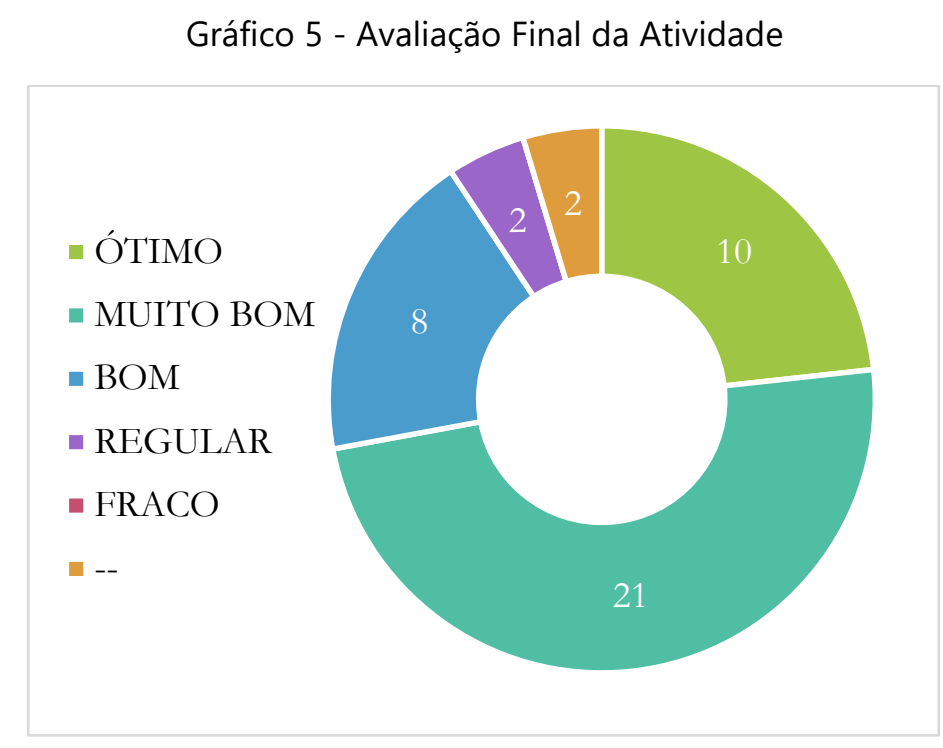

Fonte: Autores (2018).

Na parte descritiva da questão, os estudantes colocaram aspectos que reforçam o nível de engajamento dos alunos quando se traz um conteúdo mais próximo a eles, que são destacados da seguinte forma:

- "interessante principalmente na parte de novas formas de interagir" (E33).

- "foi uma ótima experiência a facilitar ao engajar na disciplina (E25). 
- "muito legal essa forma variada de aula, com exemplos em filmes" (E09).

Ao observar as respostas descritivas dos estudantes que avaliaram como "regular", percebe-se que os estudantes que fizeram essa avaliação, levaram em consideração o enredo do episódio e a relação com o público, ao invés de avaliar a atividade em si. Mas, de qualquer forma, expressa a sensação do estudante quando colocado a um material didático, que tira ele da zona de conforto:

- "apesar de mostrar uma realidade possível, mostra também como o ser humano pode ser burro para agradar os outros" (E02).

- "particularmente acredito que o episódio passa uma mensagem exagerada que constrange até mesmo os espectadores" (E43).

Houve relatos que consideraram a atividade não tão proveitosa, apesar de terem classificado ela como muito boa. Os comentários foram em relação ao tempo de duração da atividade, o que pode ser um alerta para a decisão de ter passado o filme em sala de aula. Além disso, o comentário de E05 demonstra ainda a dificuldade dos estudantes de encarar novas mídias como fonte de discussão e reflexão da teoria.

- Achei inovador, porém ocupou muito tempo de aula. Talvez fazer o mesmo com filmes e pesquisas menores (E04)

- “[...] interrompeu a aula de vídeo, e nos atrasou na matéria teórica $[\ldots] "(\mathrm{E} 05)$.

No entanto, de forma geral pode-se avaliar a atividade como exitosa, considerando a excelente percepção demonstrada pelos estudantes no uso de novas mídias, promovendo um maior engajamento da turma, mas também considerando que a crítica que estava sendo proposta no âmbito da disciplina foi absorvida bem como a crítica realizada no certame ideológico. Um dos estudantes relatou que:

- "o sentimento geral em relação ao episódio foi de nojo, porém de uma forma positiva, pois o episódio conseguiu representar muito bem a crise sócio tecnológica que enfrentamos atualmente e o que pode acontecer caso não controlemos melhor a tecnologia disponibilizada ao público" (E26). 
O comentário do estudante é uma síntese das percepções dos demais colegas, já relatadas nesse material, e mostra o quão rico é a contribuição de novas mídias e o quanto essa experiência permitiu que eles refletissem sobre o comportamento da sociedade e o uso da tecnologia.

\section{Considerações circunstanciais}

O estudo realizado permite reafirmar o quão enriquecedor é para os estudantes serem confrontados com uma mídia que está dentro do cotidiano, o que permite um questionamento crítico do estudante para novas mídias, as quais ele for assistir, mesmo que não seja uma atividade proposta pelo professor.

Observou-se também que diante da metodologia utilizada, necessita-se realizar alguns ajustes, como por exemplo, a exibição do filme em sala de aula. Em um primeiro momento, se tratando de uma disciplina de vídeo seria justificável a exibição em sala, porém considerando o comentário de alguns estudantes, observa-se um desgaste em relação ao tempo da atividade. Dessa forma, para uma próxima atividade, poderia ser proposto aos estudantes que assistissem ao filme em horário alternativo ao da sala de aula, e em um momento anterior da discussão em grupo o professor reexibiria os trechos que julga importante serem comentados.

Por fim, com base na fundamentação teórica e nos resultados apresentados na experiência, é possível afirmar que o uso dessas novas tecnologias em sala de aula são ferramentas que permitem ao professor explorar uma nova forma de sensibilizar o estudante para uma aprendizagem significativa, gerando um ser reflexivo, crítico e autônomo.

\section{Referências}

BELLONI, M. L. O que é mídia-educação. 2 ed. Campinas: Autores Associados, 2005.

BELLONI, M. L. Educação a distância e mídia-educação na formação profissional. Revista eletrônica de jornalismo científico, 2012. Disponível em:

$<$ http://www.senado.leg.br/comissoes/ce/ap/AP20111109_Maria_Belloni.pdf>. Acesso em: 22 ago. 2018. 
BROOKER, C. Charlie Brooker: the dark side of our gadget addiction. The Guardian. 2011. Disponível em: <https://www.theguardian.com/technology/2011/dec/01/charliebrooker-dark-side-gadget-addiction-black-mirror>. Acesso em: 25 jul. 2018.

CAMBRIDGE UNIVERSITY. Cambridge Dictionary. Cambridge: Cambridge University Press, 2018. Disponível em: <https://dictionary.cambridge.org/dictionary/english/ondemand >. Acesso em: 05 ago. 2018.

CRESWELL, J. W. Projeto de pesquisa: métodos qualitativo, quantitativo e misto. 3.ed. Porto Alegre: Artmed, 2010.

COUTO, E. S. Pedagogias das conexões: compartilhar conhecimentos e construir subjetividades nas redes sociais digitais. In: PORTO, C.; SANTOS, E. (Org.). Facebook e educação: publicar, curtir, compartilhar. Campina Grande: EDUEPB, 2014.

DUARTE, R. Cinema \& Educação. 3. ed. Belo Horizonte: Editora Autêntica: 2009. 104 p.

ELEÁ, I.; DUARTE, R. Mídia-Educação: Teoria e Prática. In: SANTOS, Edméa. Mídias e Tecnologias na Educação Presencial e à Distância. Rio de Janeiro: LTC, 2016. 247 p.

FERRÉS, J. Vídeo e educaşão. 2. ed. Porto Alegre: Artes Médicas, 1996. 156 p.

FERRÉS, J. Pedagogia dos meios audiovisuais e pedagogia com os meios audiovisuais. In: SANCHO, J. M. Para uma tecnologia educacional. Porto Alegre: Artmed, 1998. 327 p.

GIL, A. C. Métodos e técnicas de pesquisa social. 5 ed. São Paulo: Atlas, 1999.

INSTITUTO PRÓ-LIVRO (Brasil). Pesquisa Retratos da Leitura no Brasil. 4. ed. São Paulo, 2016. Disponível em:

<http://prolivro.org.br/home/images/2016/Pesquisa_Retratos_da_Leitura_no_Brasil__2015.pdf>. Acesso em 08 set. 2018.

KENSKI, V. M. Educaşão e tecnologias: o novo ritmo da informação. 8. ed. Campinas: Papirus, 2011. $141 \mathrm{p}$.

LAPA, A. B.; BELLONI, M. L. Educação a distância como mídia-educação. Perspectiva, Florianópolis, v. 30, n. 1, p. 175-196, mai. 2012. ISSN 2175-795X. Disponível em: $<$ https://periodicos.ufsc.br/index.php/perspectiva/article/view/2175-

795X.2012v30n1p175/22190>. Acesso em: 26 ago. 2018.

MATTAR, J. YouTube na educação: o uso de vídeos em ead. São Paulo: Universidade Anhembu Morumbi, 2009. (Relatório de pesquisa) Disponível em:

$<$ http://www.joaomattar.com/YouTube $\% 20$ na $\% 20$ Educa $\% C 3 \% A 7 \% C 3 \% A 30 \% 200 \% 20$ uso $\% 20 \mathrm{de} \% 20 \mathrm{v} \% \mathrm{C} 3 \% \mathrm{ADdeos} \% 20 \mathrm{em} \% 20 \mathrm{EaD}$.pdf>. Acesso em: 20 ago. 2018.

MATRIX, S. The Netflix Effect: Teens, Binge Watching, and On-Demand Digital Media Trends. Jeunesse: Young People, Texts, Cultures, [s.l.], v. 6, n. 1, p.119-138, jan. 2014. Disponível em:

<https://www.researchgate.net/publication/270665559_The_Netflix_Effect_Teens_Bing e_Watching_and_On-Demand_Digital_Media_Trends>. Acesso em: 23 jul. 2018.

MORAN, J. M. Ensino e aprendizagem inovadores com apoio de tecnologias. In: MORAN, J. M.; MASETTO, M.; BEHRENS, M. A. Novas tecnologias e mediação pedagógica. 13. ed. Campinas: Papirus, 2007. 173 p. 
MORAN, J. Metodologias ativas para uma aprendizagem mais profunda. In: BACICH, L.; MORAN, J. (Orgs.). Metodologias ativas para uma educação inovadora: uma abordagem teóricoprática. Porto Alegre: Penso, 2018.

MOREIRA, J. A.; MONTEIRO, A. Exploração didática de filmes educativos em ambientes virtuais de aprendizagem. Cadernos de Pedagogia no Ensino Superior, n. 21, p. 3-14, 2012. Disponível em: <http://hdl.handle.net/10400.2/2750>. Acesso em: 06 set. 2018.

MOREIRA, J. A.; NEJMEDDINE, A. O vídeo como dispositivo pedagógico e possibilidades de utilização didática em ambientes de aprendizagem flexiveis. Santo Tirso: Whitebooks, 2015.

NAPOLITANO, M. Como usar o cinema sala de aula. São Paulo: Contexto, 2009. 249 p.

NETFLIX. IR Overview: Long-Term View. 2018. Disponível em: $<$ https://www.netflixinvestor.com/ir-overview/long-term-view/default.aspx >. Acesso em: 05 ago. 2018.

PALFREY, J.; GASSER, U. Nascidos na era digital: entendendo a primeira geração de nativos digitais. Porto Alegre: Artmed, 2011.

SANTOS, E. O. Educação online: cibercultura e pesquisa-formação na prática docente. 2005. 351 f. Tese (Doutorado em Educação) - Universidade Federal da Bahia, Salvador, 2005. Disponível em: <https://repositorio.ufba.br/ri/handle/ri/11800>. Acesso em: 22 ago. 2018.

SANTOS, E. O. dos; CARVALHO, F. S. P.; PIMENTEL, M. Mediação docente online para colaboração: notas de uma pesquisa-formação na cibercultura. ETD-Educação Temática Digital, v. 18, n. 1, p. 23-42, 2016. Disponível em:

$<$ https://periodicos.sbu.unicamp.br/ojs/index.php/etd/article/view/8640749>. Acesso em: 22 ago. 2018.

SILVA, M. Sala de aula interativa. 2. ed. Rio de Janeiro: Quartet, 2001.

TACHIZAWA, T.; MENDES, G. Como fazer monografia na prática. 2. ed. Rio de Janeiro: Fundação Getúlio Vargas, 1999. 106 p.

TORRES, P. L.; KUCHARSKI, M. V. S.; MARRIOT, R. C. V. Concept Maps and the Systematization of Knowledge. In: SHEDLETSKY, L. J; BEAUDRY, J. S. (Org.). Cases on Teaching Critical Thinking through V isual Representation Strategies. 1ªed. New York: IGI, 2014. p. 494-514.

WORTHAM, J. 'Black Mirror' and the Horrors and Delights of Technology. The New York Times Magazine, 2015. Disponível em:

<https://www.nytimes.com/2015/02/01/magazine/black-mirror-and-the-horrors-anddelights-of-technology.html>. Acesso em: 25 jul. 2018.

RECEBIDO: 30/06/2019

APROVADO: 01/09/2019
RECEIVED: 06/30/2019

APPROVED: 09/01/2019
RECIBIDO: $30 / 06 / 2019$

APROBADO: 01/09/2019 